\title{
Positioning Students to Understand Urban Sustainability Strategies through Vertical Integration: Years One through Four
}

\section{Mr. MOHAMED ELZOMOR, Arizona State University}

Mohamed ElZomor has earned a B.Sc and M.Eng in Construction from the American University in Cairo, in addition to M.Sc. in Architecture with an emphasis on Design and Energy Conservation from University of Arizona. He is currently a Construction Management Ph.D. Candidate in the School of Sustainability and the Built Environment at Arizona State University. Before embarking on his academic career, he gained valuable local and international construction experience while working in the construction industry for different capacities, both in the office and the field. Mr. ElZomor worked as a Project Manager for several years and delivered complex projects, one of which was an iconic \$150 million office park.

Not only is Mohamed a specialist in the construction field, but also with extensive research within the advanced educational pedagogies, energy, and environmental disciplines. Mr. ElZomor developed an index to define small infrastructure projects' scope and associated risk. The overall goal of ElZomor's work is to leverage the integration of energy efficiency measures into construction, building design and operation processes for societal good.

\section{Prof. Kristen Parrish, Arizona State University}

Kristen Parrish is an Assistant Professor in the School of Sustainable Engineering and the Built Environment at Arizona State University (ASU). Kristen's work focuses on integrating energy efficiency measures into building design, construction, and operations processes. Specifically, she is interested in novel design processes that financially and technically facilitate energy-efficient buildings. Her work also explores how principles of lean manufacturing facilitate energy-efficiency in the commercial building industry. Another research interest of Kristen's is engineering education, where she explores how project- and experience-based learning foster better understanding of engineering and management principles. Prior to joining ASU, Kristen was at the Lawrence Berkeley National Laboratory (LBNL) as a Postdoctoral Fellow (2009-11) and then a Scientific Engineering Associate (2011-2012) in the Building Technologies and Urban Systems Department. She worked in the Commercial Buildings group, developing energy efficiency programs and researching technical and non-technical barriers to energy efficiency in the buildings industry. She has a background in collaborative design and integrated project delivery. She holds a BS and MS in Civil Engineering from the University of Michigan and a PhD in Civil Engineering Systems from University of California Berkeley. 


\section{Positioning Students to Understand Urban Sustainability Strategies through Vertical Integration: Years One through Four}

\section{Abstract}

Commonly-adopted engineering pedagogy tends to be lecture-based, and places students in a passive and predominantly secondary role (Hung et al., 2003). Research in the field of engineering education also highlights the ineffectiveness of such strategies and strongly advocates that faculty adopt advanced education strategies that actively engage learners. Citing medical education as an example, engineering education research suggests problem-based learning and vertical integration as two key strategies that will assist in facilitating the active engagement of learners.

This pedagogical implementation presents the progress from years one through four of an NSF TUES (Transforming Undergraduate Education in STEM) project that assesses the effectiveness of a vertically integrated problem-based learning (PBL) framework developed and implemented at "Arizona State University". The authors' framework integrates a lower-division construction management course, Construction Materials, Methods and Equipment (CON 252) and an upper-division civil engineering course, Urban Infrastructure Anatomy and Sustainable Development (CEE 507). The courses both address sustainability, and that provides a theme for vertical integration activities. The goal of introducing sustainability concepts is two-fold: to enhance undergraduate students' interest in and understanding of sustainability by engaging them in real-world sustainability projects; and to provide students with necessary knowledge for advancing a career in sustainability within Civil and Construction Engineering and Management (CCEM).

This paper summarizes the progress and accomplishments of the project during years one through four, documenting the lessons learned each year and describing the vertical integration PBL framework developed throughout the project. Framework development follows a continuous improvement process, and it is updated according to student feedback, feedback from the project evaluators, and the impressions of the instructors. Upper division students recognized the parallels between the vertical integration and future professional collaborations with lessexperienced team members. They also report being able to teach useful concepts and skills, such as citing sources, to lower division students. Finally, they understood the value of interacting with less-skilled individuals for developing their management skills. It is worth noting that the lower division students demonstrated improvements in their interdisciplinary interaction confidence skills as well.

\section{Introduction}

Sustainability is identified as a priority research area for the civil and construction engineering and management (CCEM) industries (Back, 2008). The tightening of human and environmental constraints is driving the engineering profession to think more rigorously about sustainability and the environment. A growing number of academics and professionals in CCEM infuse sustainability principles, including alternative energy, energy efficiency, and others, into their research. Sustainability is generally taught in upper-level classes, yet lower-level classes may include some supplemental sustainability course. Although undergraduate students may have an 
interest in sustainability, their exposure to it comes later in their educational curriculum (Dancz, 2016).

Sustainability has been identified as a "wicked problem" (Brundiers and Wiek, 2011, Seager et al., 2012), unstructured and thus difficult to model, with multiple interconnected and integrated aspects that spans policy domains and levels of government. Research indicates PBL is an appropriate strategy for teaching students to engage in complex problem solving, and indeed may be one of the only effective methods for doing so (Shepherd and Cosgrif, 1998, Tomkinson et al., 2008). The vertically-integrated problem-based learning (PBL) framework developed in the course of this TUES project provides undergraduate students with both knowledge and tools needed to address urban sustainability issues in their future careers, whether in industry or academe. This framework is replicable and can thus be deployed across universities as part of the CCEM curriculum.

In this TUES project, the researchers develop a problem-based learning framework that (1) introduces sustainability earlier in the undergraduate curriculum, and (2) provides an opportunity for vertical integration across courses within CCEM curriculum. The goal of introducing sustainability concepts is two-fold: to enhance undergraduate students' interest in and understanding of sustainability by engaging them in real-world sustainability projects; and to provide students with necessary knowledge for advancing a career in sustainability within CCEM.

The PBL framework is developed and implemented at "Arizona State University" between a lower-division construction management course, Construction Materials, Methods and Equipment (CON252) and an upper-division/graduate cross-disciplinary course between civil engineering course, sustainability, and planning, Urban Infrastructure Anatomy and Sustainable Development (CEE 507). CON252 focuses on the building design and construction process, ranging from excavation to material choice to various building systems. CEE 507 focuses on infrastructure systems from the technical and environmental perspectives and examines the interdependences between these infrastructures.

\section{Motivation and Vision}

Introductory courses tend to be required for lower-division students and these courses act as prerequisites for upper-division courses that tend to be more discipline-specific and thus, may be more engaging for students. Introductory courses provide fundamental information and knowledge needed for upper-division courses. This framework continues throughout an academic course map, forming a linear advancement. Figure 1 shows this progression.

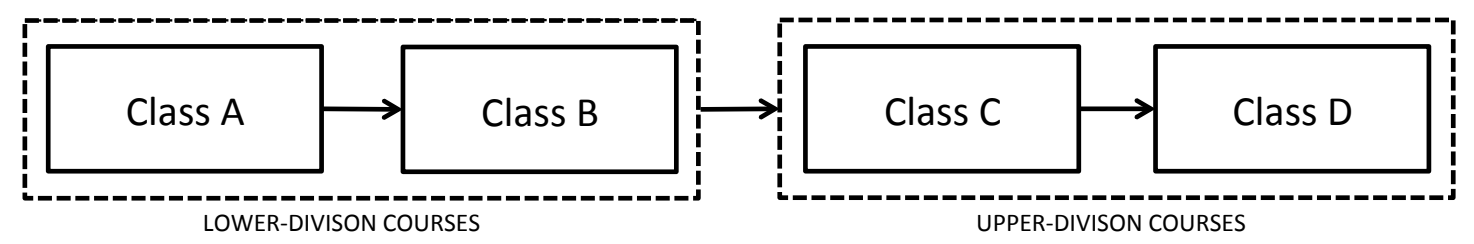

Figure 1: Linear Progression of Academic Courses 
Class A provides knowledge needed for Class B, Class B provides knowledge needed for Class C, and so forth. Therefore, earlier classes such as Classes A and B are more focused on the fundamental concepts which then help students in their upper-division courses that are more conceptual and realistic (e.g., higher levels of Blooms). Though this progression is logical, it can result in lack of interest among students and therefore lack of retention. While there is a connection between more conceptual, upper-division courses and more fundamental, lowerdivision courses, this is hard to see in the lower-division course due to the lack of exposure to these upper-division courses in the earlier years. The authors have therefore aimed to create a framework that allows for a connection between upper and lower-division courses, as shown in the figure below.

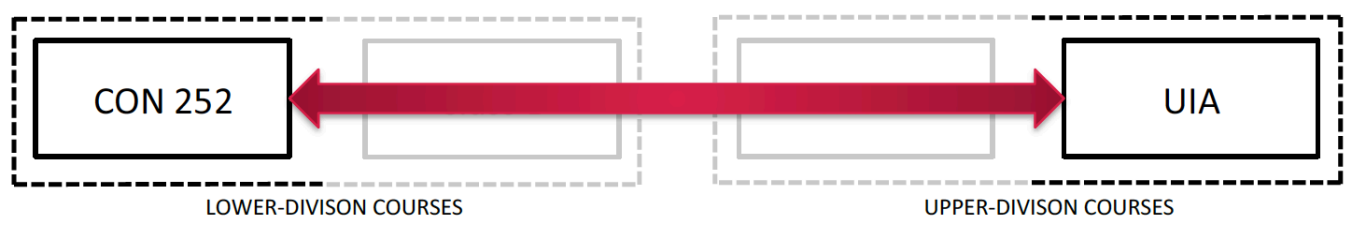

Figure 2: Vertically Integrated PBL Framework Course Connection

This approach presents a framework that addresses the gap between upper and lower division courses through vertical integration and PBL. This framework leverages problem-based learning to support in-class student engagement and retention in science, technology, engineering and mathematics (STEM) fields. Vertical integration supports out-of-classroom engagement, which in turn serves student retention in engineering. The utilized "vehicle" for vertical integration is course projects, which lend themselves nicely to PBL. This framework will ultimately be transferable among different course types, educational levels, and universities. Specific aspects of this framework will be provided to successfully implement this vertically integrated PBL framework in another setting. This paper discusses and explores both the creation and implementation of this framework.

\section{Implementation of the Vertically Integrated PBL Framework}

The vertical integration PBL framework was implemented four times. These four implementations are the pilot approach, second implementation Spring 2015, the third implementation Spring 2016, and the fourth implementation Spring 2017. Previous ASEE papers (e.g., (ElZomor et al., 2016, Mann et al., 2015) present prior implementations. This section presents lessons learned from past implementations, highlighting the changes in approach and evaluation of the vertically-integrated PBL framework. This section also presents the Spring 2017 implementation.

IV.i. The Pilot Approach (Spring 2014)

The authors learned that in not stressing the need to integrate two courses, students felt disconnected from the vertical integration. Further, the authors learned that each student from CON 252 should have a face-to-face interaction with at least one CEE 507 student and vice versa. Mann et al. (2015) describe this implementation in more details. 
IV.ii. Second Implementation: Spring 2015

Mann et al. (2015) describe the Spring 2015 implementation in detail. Lessons learned include:

- Formal evaluation improves the ability to update the framework

- Evaluation should be set up to facilitate longitudinal tracking of students' experiences

- Framework is more successful with face-to-face interactions of students

- Course projects need to be aligned to make the integration more meaningful to both CON 252 and CEE 507 students

IV.iii. Third Implementation: Spring 2016

ElZomor et al. (2016) describe the Spring 2016 implementation in detail. Major findings for this implementation, which were documented following the ASEE 2016 Conference, include:

- Finding 1: More interaction is effective when students exchange useful information The majority of students in each class did not feel the integration was an organic portion of the course projects; focus group participants underscored that increased alignment of projects and dependence on counterparts would improve the experience.

- Finding 2: Preparation for collaborations in future careers The vertical integration helped students to develop collaborative skills that will be useful in their careers. Both course projects included significant collaboration with peers plus collaboration through the vertical integration. Upper division students and lower division students assessed in surveys reported that their skills improved in communicating with others and managing others. Upper division students in a focus group recognized the parallels between the vertical integration and future professional collaborations with lessexperienced team members. It was an exercise in "how I would deal with people who are not at the same academic level, who do not have enough time, who have a lot of work to do," related one upper division student.

- Finding 3: Vertical integration benefits lower division and upper division students Both lower division and upper division students supported vertical integration as a pedagogical tool, though they felt that implementation in Spring 2016 did not meet their expectations.

- Finding 4: Improved collaboration applications and processes will draw students into partnership Students appreciate a central virtual location but do not think that Box.com is the best choice of application. They found Box difficult to sift through and unhelpful to communicate, especially since communication was often routed through a single group member and so they suggested Blackboard or Google Drive instead. Students desired more opportunity to interact virtually and index information.

IV.iv. Fourth Implementation: Spring 2017

The fourth implementation was based on the lessons learned from all previous implementations. However, since the Spring 2016 implementation was the most advanced and effective according to students, the fourth implementation (Spring 2017) incorporated as many of the students' and evaluators' recommendations as possible, and tried to address all other comments and feedback. The framework features: 
- Required face-to-face interactions between CON 252 and CEE 507 students: The course instructors aligned their syllabi and project rubrics to facilitate and incentivize cooperation between undergraduate and graduate students. Both instructors gave class periods "off" to allow students to "make up" those classroom hours during vertical integration activities.

- Foster dependence between lower division and upper division students: The instructors ensured that vertical integration activities require active participation in the vertical integration. In both courses, the instructors set aside course credit specifically for the integration activities; further, each instructor required incorporating results from the integration activity into the course project to earn an A on the project.

- Explain to current students how former students' experiences have shaped the curriculum implementation: The instructors are transparent about how they change their curriculum design based on feedback from former students. Prioritizing student input helps to ensure that the curriculum's fullest impact will be realized, as students are the ones who experience the limitations or opportunities of curricular decisions.

- Integrate professional and interesting means to define the scope of the integrative project: The instructors renewed their emphasis on problem-based learning that mimics career situations by utilizing tools adopted by construction and engineering professionals. In particular, they implement the Project Definition Rating Index (PDRI) in both courses to help students identify those activities required to complete a construction project. In so doing, not only do the students gain awareness of tools professionals use, they also broaden their own understanding of the scope of an actual engineering and construction project.

\section{IV.iv.1. Best Practices: Spring 2017}

After four years of implementing vertical integration activities, a few best practices emerge:

- Align projects; Project scopes and components must overlap such that upper- and lower-division students understand the usefulness of their own expertise and the usefulness of the expertise of the students in the other course.

- Reward utilization: Students, especially lower division students, need incentives to provide information to, and utilize information from, another course. Without the reward of points on the project rubric, students may not commit to the integration.

- Embed the lower division Teaching Assistant (TA) in the upper division course: Facilitating collaboration between courses works best when an authority to the lower division students also participates in the upper division course. The most effective facilitator seems to be a graduate student enrolled in the upper division course who also serves as a TA for the lower division course.

- Coordinate course meeting times: Rather than placing the burden of coordinating several students' schedules on the students themselves, instructors should coordinate course schedules so that vertical integration activities can occur during class times, when all students are already participating in the class. 


\section{Requirements and Challenges}

This framework requires courses to be offered during the same semester. The assignments require students from both courses spend time outside of the classroom to collaborate. Moreover, the instructors have to dedicate time to planning the logistics for vertical integration, including aligning projects and syllabi, providing time and space for integration activities, and providing a clear set of expectations around vertical integration. It is strongly advisable to include a third party evaluator to ensure unprejudiced feedback and results.

\section{Conclusion}

Results suggest more collaborative projects support vertical integration, as these "force" students to integrate around a common topic. PBL provides a focal point for conversations throughout the semester, as students from each course visit the other course to introduce their unique course projects, and collaboratively develop solutions. Consistent communication between the two courses supports professional skill development in both upper- and lower-division student populations.

\section{Acknowledgments}

This research is funded by grant DUE- 1245205 from the National Science Foundation (NSF). This support is gratefully acknowledged. Any opinions, findings, conclusions, or recommendations expressed in this paper are those of the writers and do not necessarily reflect the views if the NSF. 


\section{References}

BACK, W. E. 2008. CII Research Needs: An Academic Perspective. Construction Industry Institute. Houston, Texas $U S<$ https://www. construction-institute. org/scriptcontent/rtc2008_acl. pdf>(date accessed: 06 April 2010).

BRUNDIERS, K. \& WIEK, A. 2011. Educating students in real-world sustainability research: vision and implementation. Innovative Higher Education, 36, 107-124.

DANCZ, C., KETChMAN, K., BURKE, R., HOTTLE, T., PARRISh, K., BILEC, M., \& LANDIS, A, 2016. Utilizing Civil Engineering Senior Design Capstone Projects to Evaluate Students Sustainability Education Across Engineering Education. Manuscript submitted for publication.

ELZOMOR, M., MANN, C., PARRISH, K. \& CHESTER, M. 2015. Positioning Students to Understand Urban Sustainability Strategies through Vertical Integration: Years 1 through 3. 123rd ASEE Annual Conference, 26-29 June 2016 New Orleans, LA. American Society for Engineering Education, 4 pp. .

HUNG, I., CHOI, A. C. \& CHAN, J. S. 2003. An integrated problem-based learning model for engineering education. International Journal of Engineering Education, 19, 734-737.

MANN, C., PARRISH, K. \& CHESTER, M. 2015. Positioning Students to Understand Urban Sustainability Strategies through Vertical Integration. 122nd ASEE Annual Conference, 14-17 June 2015 Seattle, WA. American Society for Engineering Education, 4 pp. .

SEAGER, T., SELINGER, E. \& WIEK, A. 2012. Sustainable engineering science for resolving wicked problems. Journal of agricultural and environmental ethics, 25, 467-484.

SHEPHERD, A. \& COSGRIF, B. 1998. Problem-based learning: A bridge between planning education and planning practice. Journal of Planning Education and Research, 17, 348-357.

TOMKINSON, B., TOMKINSON, R., DOBSON, H. \& ENGEL, C. 2008. Education for sustainable developmentan inter - disciplinary pilot module for undergraduate engineers and scientists. International Journal of Sustainable Engineering, 1, 69-76. 